\title{
Correction to: A Characterization of Amenable Groups by Besicovitch Pseudodistances
}

Silvio Capobianco and Pierre Guillon

\section{Correction to: \\ Chapter "A Characterization of Amenable Groups by Besicovitch Pseudodistances" in: H. Zenil (Ed.): Cellular Automata and Discrete Complex Systems, LNCS 12286, https://doi.org/10.1007/978-3-030-61588-8_8}

The authors have made a correction to the authorship of this conference paper [1]. The third author listed as Camille Noûs is fictitious (http://www.cogitamus.fr/camilleen. html) and as such does not fulfill Springer Nature's requirements for authorship. The correct authorship list is: Silvio Capobianco and Pierre Guillon.

[1] Capobianco, S., Guillon, P.: A Characterization of Amenable Groups by Besicovitch Pseudodistances. In: Zenil, H. (ed.) AUTOMATA 2020. LNCS, vol. 12286, pp. 99-110. Springer, Cham (2020). doi: https://doi.org/10.1007/978-3-030-61588-8_8

The updated version of this chapter can be found at https://doi.org/10.1007/978-3-030-61588-8_8

(C) IFIP International Federation for Information Processing 2021

Published by Springer Nature Switzerland AG 2021. All Rights Reserved

H. Zenil (Ed.): AUTOMATA 2020, LNCS 12286, p. C1, 2021.

https://doi.org/10.1007/978-3-030-61588-8_12 